\title{
Comparison of the Intraoperative Outcomes of Intrauterine Instillation of Epsilon-Aminocaproic Acid and Intravenous Oxytocin in Hysteroscopy Surgeries
}

\author{
Manizheh Sayyahmelli ${ }^{*}$, Rogayeh Moosazade ${ }^{1}$, Parvin Mostafa Gharabaghi ${ }^{1}$, Fateme Nazari ${ }^{1}$
}

\begin{abstract}
Objectives: As the technique of choice, hysteroscopy can be used in visualizing and treating intrauterine pathologies such as polyps, septa, fibroids and endometrial hyperplasia. The best visualization, however, is attained when the endometrium is flat or atrophic; or a pre-existing active bleeding is minimal or suspended during hysteroscopy. Both epsilon-aminocaproic acid (EACA) and oxytocin have been found effective against active bleeding. The present work aimed to compare the efficacy and safety of intrauterine EACA and intravenous oxytocin in the management of intractable uterine bleeding in candidates of operative hysteroscopy.

Materials and Methods: In this single-center, observer-blinded clinical trial, 144 candidates of operative hysteroscopy with intractable moderate uterine bleeding were randomized in two groups, receiving either intrauterine instillation of EACA ( $2 \mathrm{~g}$ in $1 \mathrm{~L}$ of $5 \%$ dextrose serum, $\mathrm{n}=72)$ or intravenous oxytocin $(10 \mathrm{IU} / \mathrm{L}, \mathrm{n}=72)$. The operator graded the severity of intraoperational bleeding ( $\mathrm{I}=$ no to $\mathrm{V}=$ most severe). Serum hematocrit and hemoglobin changes, intra- and post-operational complications, the mean operative time, and the mean volume of the employed media were also recorded and compared between the two groups. Results: The two groups were comparable in terms of age, gravidity and parity. Grades I, II and III of intraoperational bleeding were reported in $79.2 \%, 18.1 \%$ and $2.8 \%$ of cases in the EACA group, and $18.2 \%, 65.3 \%$ and $16.7 \%$ of the cases in the oxytocin group, respectively $(P<0.001)$. While the two groups were also comparable in terms of serum hematocrit and hemoglobin changes, intraand post-operation complications (none in both groups) and the mean volume of the media intraoperatively, the mean operative time was significantly shorter in patients who received intrauterine instillation of EACA $(10.28 \pm 3.24$ minutes vs. $11.81 \pm 4.62$ minutes, $P=0.02$ ).

Conclusion: Owing to less severe intraoperative hemorrhage and shorter duration of operation in the group who received intrauterine instillation of EACA than those with intravenous injection of oxytocin, we recommend the intrauterine EACA in managing intractable uterine bleeding in candidates of hysteroscopy.

Keywords: Aminocaproic acid, Epsilon, Hysteroscopy, Oxytocin, Uterine hemorrhage
\end{abstract}

\section{Introduction}

Abnormal uterine bleeding is a common cause of referring women to gynecologists $(1,2)$. After initial evaluation and excluding pregnancy-related complications, neoplasms and coagulative abnormalities, many patients could be managed conservatively. Any refractory bleeding before the age of 35 years and any abnormal bleeding beyond the age of 35 years necessitate intrauterine histopathologic examinations. First of all, an outpatient biopsy is performed, but hysteroscopic intracavitary examinations are indicated if the sample is unsatisfactory or the bleeding continues despite an adequate proper management. Persistent bleeding, however, may cause the procedure to be unsuccessful. So, various compounds such as oral or vaginal danazol (3), gonadotropin-releasing hormone agonists (GnRHa) (4), cabergoline and progestins (5) have been ever tried to diminish intraoperative hemorrhage. These compounds can modify the surgical environment by decreasing intraoperative bleeding to some extent that the amount of media required for uterine distension is reduced, a better visibility is provided, and the surgical time is shortened. Nevertheless, they are expensive and sometimes along with significant complications. In addition, they need to be administered soon enough before the operation in order to give time to their beneficial effects to take place. Antifibrinolytic compounds are also known as potent anti-bleeding agents. They have been also found effective against uterine bleeding, with a reported efficacy of $35 \%-56 \%$ (6).

Epsilon-aminocaproic acid (EACA) is an antifibrinolytic agent. It is used intravenously at a rate of $50-60 \mathrm{mg} / \mathrm{kg} \mathrm{ev}$ ery 4-6 hours for the control of bleeding in patients with coagulopathies. At a dose of $1 \mathrm{~g}$ in $1 \mathrm{~L}$ of serum dextrose, EACA has been successfully used in controlling uterine bleeding (7), $2.5 \mathrm{~g}$ solution as bladder instillation to treat the intractable hematuria (8) and intravesically by continuous bladder irrigation involves a loading dose of 5 $\mathrm{g}$ followed by $1 \mathrm{~g} / \mathrm{h}$ for 8 hours until bleeding stops (9). The side effects are nausea, vomiting, diarrhea, confusion, headache, weight gain and leg cramp, which have been re-

Received 4 May 2015, Accepted 17 September 2015, Available online 12 October 2015

${ }^{1}$ Department of Obstetrics and Gynecology, Women's Reproductive Health Research Center, Tabriz University of Medical Science, Tabriz, Iran *Corresponding author: Manizheh Sayyahmelli, Department of Obstetrics and Gynecology, Women's Reproductive Health Research Center, Tabriz University of Medical Science, Tabriz, Iran. Tel: +989141158085, Email: manizheh.sayyahmelli@gmail.com 
ported with long-term use of the drug (10).

Intravenous oxytocin, on the other hand, is an uterotonic medication that reduces bleeding through stimulating the uterine smooth muscle contraction and subsequent vascular luminal narrowing (11). Although generally considered as a rather safe medication, oxytocin may cause serious complications such as urinary retention and hypotension (12).

This study seeks to compare efficacies and side effects of using EACA at a higher than conventional dose and intravenous oxytocin in females with intractable moderate uterine bleeding.

\section{Materials and Methods}

In this randomized clinical trial (registration No. IRCT201409235283N10), a total of 144 females with intractable moderate uterine bleeding who were candidates for hysteroscopic intervention received either intrauterine EACA or intravenous oxytocin in Tabriz Alzahra hospital from January 2013 to December 2014.

Patients with cardiovascular, pulmonary, renal or hepatic diseases; those with upper urinary system bleeding, acute intravascular thrombosis, metabolic abnormalities such as hypertriglyceridemia and diabetes mellitus, cervical cancer, uterine cancer, submucosal fibroids of the uterus larger than $5 \mathrm{~cm}$, genital active infections and uterine septum; as well as pregnant women, patients who required intraoperative blood transfusion, and those on anticoagulant medications were excluded.

The control of uterine bleeding was considered as the primary outcome in this study. With an assumption of $20 \%$ proportional superiority of EACA over oxytocin in decreasing uterine bleeding, alpha $=0.05$, and power $=80 \%$, 130 patients were needed. Finally, this figure was augmented to 144 patients (72 cases in each group). The randomization was accomplished using the RandList software (version 1.2, Germany). One group received intrauterine instillation of EACA ( $2 \mathrm{~g}$ in $1 \mathrm{~L}$ of $5 \%$ dextrose serum) and the other group received intrauterine instillation of $5 \%$ dextrose serum coupled with intravenous oxytocin (10 IU/L).

The serum temperature was similar in both groups. A visual scale was used to report the amount of bleeding; 0 : no bleeding; I: mild bleeding; II: moderate bleeding; III: severe bleeding; and IV: severe bleeding with clots.

The complications of anesthesia were regarded as hypotension and/or heart rate variability. Routine tests such as blood grouping, Rh determination, serum electrolyte analysis, partial thromboplastin time (PTT) assessment and platelet count, Pap smear, endometrial official biopsy, and transvaginal ultrasonography were performed in all patients, preoperatively. The surgeon was unaware of the grouping or the type of medications. The anesthetic method was similar in both groups.

The statistical analysis was performed using the SPSS 16. Independent samples $t$ test and the chi-square test were used for comparisons. A $P$ value $\leq 0.05$ was considered statistically significant.

\section{Results}

Patients' demographic data and study variables in both groups are summarized in Table 1. Accordingly uterine bleeding was significantly more severe in the oxytocin group than in EACA receivers. In addition, the mean time of operation was significantly longer in the oxytocin group. The remaining variables did not differ significantly between the two groups.

\section{Discussion}

Hysteroscopy is best performed when the endothelium is thin, because the uterine cavity is large enough; the hysteroscopic examination is facilitated; removing intrauterine pathologies is easier; the amount of required media is low; the odd of hysteroscopy-related complications is diminished; and the patient is more satisfied with the procedure and its outcome (13).

In the present work the efficacy and complications of using EACA and intravenous oxytocin were compared in candidates of hysteroscopy due to irregular uterine bleedings. On this basis the amount of bleeding and the time of operation decreased more significantly by using EACA compared to oxytocin. At the same time, no anesthetic complications or postoperative problems occurred.

EACA is a medication that is approved by the Food and Drug Administration (FDA) primarily for the treatment of ovulatory bleeding (14). Many previous studies have recommended it for the prevention of fibrinolysis and bleeding (15-18). EACA is an antifibrinolytic analogue of lysine and prevents activation and conversion of plasminogen to plasmin on fibrin surface (19). This effect is achieved by the attachment of plasminogen to lysine $\mathrm{C}$-terminal remnants on relatively degraded fibrin molecules and consequently, the location of attachment of plasminogen that is essential for the development of plasmin is occupied (20). In nonhuman models such as animals with infused plasmin or a plasminogen activator, EACA was able to prevent bleeding $(21,22)$.

As stated before, inhibitors of fibrinolysis such as EACA are generally used in patients with increased fibrinolysis. However, two studies by Pinder et al and Ross et al concluded that in both animal and human models this medication could cause cessation of bleedings secondary to other mechanism $(23,24)$.

Increased levels of plasminogen activators have been found in the endometrium of women with severe menstrual hemorrhage. Accordingly, some studies such as those performed by Sayyah-Melli et al and Shokeir et al used parenteral or oral EACA successfully in females with abnormally large amounts of menstrual hemorrhage $(25,26)$.

On the other hand, oxytocin, which is routinely used for induction or reinforcement of labor, has been also used in treating postpartum bleeding. Intravenous oxytocin is a medication with a short half-life (4-10 minutes). So, an advantage of the intravenous use of this medication in hysteroscopy is maintaining the uterine contractility during the procedure (27). Although oxytocin is generally 
Table 1. Patients' Characteristics and Study Variables in Two Study Groups

\begin{tabular}{|c|c|c|c|}
\hline Variable & Oxytocin ( $n=72)$ & EACA $(n=72)$ & $P$ Value \\
\hline Age $(y)$ & (70 to 25 ) $41.67 \pm 8.00$ & (76 to 28 ) $41.21 \pm 8.60$ & 0.74 \\
\hline Gravidity & (12 to 0 ) $3.32 \pm 2.62$ & (12 to 0 ) $2.64 \pm 1.84$ & 0.07 \\
\hline Parity & (10 to 0 ) $2.68 \pm 2.08$ & (10 to 0 ) $2.15 \pm 1.58$ & 0.09 \\
\hline \multicolumn{4}{|l|}{ Cause of admission } \\
\hline Vaginal bleeding & $59(81.9)$ & $56(77.8)$ & 0.53 \\
\hline Spotting & $13(18.1)$ & $16(22.2)$ & \\
\hline Disease duration (month) & (60 to 2$) 15.09 \pm 1.81$ & (60 to 1$) 12.10 \pm 1.64$ & 0.22 \\
\hline Intraoperative bleeding & & & $<0.001 *$ \\
\hline Mild & $13(18.1)$ & $57(79.2)$ & \\
\hline Moderate & $47(65.3)$ & $13(18.1)$ & \\
\hline Severe & $12(16.7)$ & $2(2.8)$ & \\
\hline \multicolumn{4}{|l|}{ Hematocrit (\%) } \\
\hline Preoperative & (48 to 29 ) $38.13 \pm 4.29$ & (48 to 27 ) $38.05 \pm 3.74$ & 0.91 \\
\hline Postoperative & (46 to 26 ) $36.22 \pm 3.84$ & (48 to 23 ) $36.61 \pm 3.98$ & 0.55 \\
\hline Change & ( 2 to -10$)-1.91 \pm 0.22$ & (5 to -12$)-1.44 \pm 0.29$ & 0.19 \\
\hline \multicolumn{4}{|l|}{ Hemoglobin (mg/dL) } \\
\hline Preoperative & (16 to 7$) 12.71 \pm 1.43$ & (16 to 9 ) $12.68 \pm 1.25$ & 0.90 \\
\hline Postoperative & (15 to 8$) 12.07 \pm 1.8$ & (16 to 7$) 12.20 \pm 1.33$ & 0.55 \\
\hline Change & (0.67 to -3.27$)-0.64 \pm 0.07$ & (1.67 to -4$)-0.48 \pm 0.10$ & 0.17 \\
\hline Operation time (min) & (40 to 5 ) $11.81 \pm 4.62$ & (20 to 5 ) $10.28 \pm 3.24$ & $0.02 *$ \\
\hline Serum volume (L) & (6 to 1 ) $2.03 \pm 0.98$ & (4 to 1 ) $1.85 \pm 0.75$ & 0.20 \\
\hline \multicolumn{4}{|l|}{ Serum $\mathrm{Na}(\mathrm{meq} / \mathrm{dL})$} \\
\hline Preoperative & (145 to 134$) 139.32 \pm 2.48$ & (144 to 133 ) $138.96 \pm 2.75$ & 0.41 \\
\hline Postoperative & (145 to 133 ) $138.64 \pm 2.33$ & (146 to 134$) 138.60 \pm 2.75$ & 0.92 \\
\hline Change & (7 to -5$)-0.68 \pm 0.34$ & (7 to -5$)-0.36 \pm 0.30$ & 0.48 \\
\hline \multicolumn{4}{|l|}{ Serum K (meq/dL) } \\
\hline Preoperative & (5 to 4$) 3.94 \pm 0.24$ & (5 to 3 ) $3.90 \pm 0.27$ & 0.27 \\
\hline Postoperative & (5 to 3 ) $3.85 \pm 0.26$ & (5 to 3 ) $3.84 \pm 0.29$ & 0.95 \\
\hline Change & (0 to -1$)-0.10 \pm 0.03$ & (1 to -1$)-0.05 \pm 0.03$ & 0.32 \\
\hline
\end{tabular}

Abbreviation: EACA, epsilon-aminocaproic acid.

regarded as a safe medication, it may result in tachycardia and hypotension, negative inotropism, and antiplatelet or antidiuretic consequences (11). A beneficial effect of oxytocin in preventing postpartum bleeding has been emphasized in some reports, as well $(11,28)$. Thomas et al also showed that the intravenous administration of oxytocin during hysteroscopic myomectomy is very effective in diminishing intraoperative bleeding (29).

By now, only two studies have investigated the effect of fibrinolytic inhibitors in preventing bleeding during hysteroscopy. In one of these two studies, Sayyah-melli et al examined the intrauterine instillation of EACA during hysteroscopy using 140 patients divided into two intervention and control groups. Both groups received 5\% dextrose as the uterine dilatator. The intervention group received EACA in each $1 \mathrm{~L}$ of serum. Finally, 120 patients completed this study. Comparing the two groups showed that the uterine bleeding was significantly less in the intervention group, but the time of operation did not differ significantly. Intraoperative and postoperative complications were also similar. Finally, they concluded that intrauterine instillation of EACA during hysteroscopic control of uterine bleeding is effective in reducing hemorrhage and providing a clearer field of view and so, it was recommended (7). Our results are in conformity with this report. In the second study, Luisi et al compared the efficacy and safety of tranexamic acid and oxytocin in preventing bleeding during hysteroscopic myomectomy. Tranexamic acid is a drug similar to EACA and acts with the same mechanism. This study showed that, in contrast to ours, oxytocin was superior in stabilizing hemodynamic state and hematologic profile. It was also more effective in reducing blood transfusion (12). It should be noted that although tranexamic acid and EACA are similar drugs, their action might differ in preventing uterine bleeding. Further studies are needed in this regard.

High efficacy of EACA in reducing bleeding has been emphasized in another series on patients with spinal surgeries (22). Triolo et al also reached a similar conclusion in an animal model in which dogs underwent oophorectomy, hysterectomy and orchiectomy (30). It has been assumed that a thinner endometrium reduces the risk of absorption of electrolytes and their serum changes through facilitating hysterectomy and reducing the amount of required media. Therefore, the probability of anesthetic complications decreases proportionally in such cases (13). No such complications in the present study confirm this assumption.

On the other hand, it should be noted that the therapeutic index of EACA is very wide. In animal models, the administration of EACA to a maximum dose of $0.5 \mathrm{~g} / \mathrm{kg}$ has been found safe (30). No complication pre- and postoperatively 
in our patients confirm the safety of the employed dose of EACA in the current study.

\section{Conclusion}

This study showed that intrauterine instillation of EACA during hysteroscopic procedure is associated with diminished intraoperative bleeding, better visualization of the operative field and a shortened procedure time.

\section{Ethical Issues}

Written informed consents were obtained from the participants. The ethics committee of the Tabriz University of Medical Sciences approved this study.

\section{Conflict of Interests}

The authors declare no conflict of interests.

\section{Financial Support}

The researchers received no financial support or grant from any funding agency in the public and commercial sectors.

\section{Acknowledgments}

This work was supported fully by Women's Reproductive Health Research Center of Tabriz University of Medical Sciences.

\section{References}

1. Abrishami A, Chung F, Wong J. Topical application of antifibrinolytic drugs for on-pump cardiac surgery: a systematic review and meta-analysis. Can J Anaesth. 2009;56(3):202-212. doi:10.1007/s12630-008-9038-x.

2. Belko JS, Warren R, Regan EE, Simpson RG. Induced fibrinolytic activity and hypofibrinogenemia. Effect of epsilon-amino-caproic acid. Arch Surg. 1963;86(3):396-401.

3. Berenholtz SM, Pham JC, Garrett-Mayer E, et al. Effect of epsilon aminocaproic acid on red-cell transfusion requirements in major spinal surgery. Spine (Phila Pa 1976) 2009;34(19):2096-2103. doi: 10.1097/BRS.0b013e3181b1fab2.

4. Bongers MY, Mol BW, Brolmann HA. Current treatment of dysfunctional uterine bleeding. Maturitas 2004;47(3):159-174. doi:10.1016/j. maturitas.2003.08.002.

5. Cooke I, Lethaby A, Farquhar C. Antifibrinolytics for heavy menstrual bleeding. Cochrane Database Syst Rev. 2000:4(4):Cd000249. doi:10.1002/14651858. cd000249.

6. Fernandez H, Kadoch O, Capella-Allouc S, Gervaise A, Taylor S, Frydman R. [Hysteroscopic resection of submucous myomas: long term results]. Annals de Chirurgie. 2001;126(1):58-64. French. doi:10.1016/ S0003-3944(00)00458-2.

7. Henry DA, Carless PA, Moxey AJ, et al. Antifibrinolytic use for minimising perioperative allogeneic blood transfusion. Cochrane Database Syst Rev. 2011;3:Cd001886. doi:10.1002/14651858.
CD001886.pub2.

8. Hoylaerts M, Lijnen HR, Collen D. Studies on the mechanism of the antifibrinolytic action of tranexamic acid. Biochim Biophys Acta. 1981;673:7585.

9. Ker K, Edwards P, Perel P, Shakur H, Roberts I. Effect of tranexamic acid on surgical bleeding: systematic review and cumulative meta-analysis. Bmj 2012;344:e3054. doi:10.1136/bmj.e3054.

10. Lakhani A, Raptis A, Frame D, et al. Case report: Intravesicular instillation of E-aminocaproic acid for patients with adenovirus-induced hemorrhagic cystitis. Bone Marrow Transplant 1999;24:1259-60. doi: 10.1038/sj.bmt.1702040.

11. Lakhani KP, Marsh MS, Purcell W, Hardiman P. Uterine artery blood flow parameters in women with dysfunctional uterine bleeding and uterine fibroids: the effects of tranexamic acid. Ultrasound Obstet Gynecol. 1998;11(4):28328-5. doi:10.1046/j.14690705.1998.11040283.x.

12. Luisi S, Razzi S, Lazzeri L, Bocchi C, Severi FM, Petraglia F. Efficacy of vaginal danazol treatment in women with menorrhagia during fertile age. Fertil Steril. 2009;92(4):1351-4. doi:10.1016/j. fertnstert.2008.08.017.

13. MacGillivray RG, Tarabichi SB, Hawari MF, Raoof NT. Tranexamic acid to reduce blood loss after bilateral total knee arthroplasty: a prospective, randomized double blind study. J Arthroplasty. 2011;26(1):24-28. doi:10.1016/j.arth.2009.11.013.

14. Manikandan R, Kumar S, Dorairajan LN. Hemorrhagic cystitis: a challenge to the urologist. Indian J Urol. 2010;26(2):159-166. doi:10.4103/09701591.65380.

15. Mannucci PM. Hemostatic drugs. N Engl J Med. 1998;339:245-253. doi:10.1056/nejm199807233390407.

16. Mannucci PM. Treatment of von Willebrand's Disease. N Engl J Med. 2004;351:683-694. doi: 10.1056/NEJMra040403.

17. Marin LM, Iazbik MC, Zaldivar-Lopez S, Guillaumin J, McLoughlin MA, Couto CG. Epsilon aminocaproic acid for the prevention of delayed postoperative bleeding in retired racing greyhounds undergoing gonadectomy. Vet Surg. 2012;41(5):594-603. doi: 10.1111/j.1532-950X.2012.00965.x.

18. Marret H, Fauconnier A, Chabbert-Buffet N, et al. Clinical practice guidelines on menorrhagia: management of abnormal uterine bleeding before menopause. Eur J Obstet Gynecol Reprod Biol. 2010;152(2):133-137. doi:10.1016/j. ejogrb.2010.07.016.

19. Melli MS, Farzadi L, Madarek EO. Comparison of the effect of gonadotropin-releasing hormone analog (Diphereline) and Cabergoline (Dostinex) treatment on uterine myoma regression. Saudi Med J. 2007;28(3):445-450.

20. Mousa SA, Yassen AM, Alhadary HS, Sadek EES, Abdel-Hady EL. Hematological profile and 
transfusion requirement during hysteroscopic myomectomy: a comparative study between oxytocin and tranexamic acid infusion. Egyptian J Anaesthesia 2012;28(2):125-132. doi:10.1016/j.egja.2011.12.003.

21. Murphy DJ, MacGregor H, Munishankar B, McLeod G. A randomised controlled trial of oxytocin 5IU and placebo infusion versus oxytocin 5IU and 30IU infusion for the control of blood loss at elective caesarean section--pilot study. ISRCTN 40302163. Eur J Obstet Gynecol Reprod Biol. 2009;142(1):30-33. doi:10.1016/j.ejogrb.2008.09.004.

22. Perel P, Al-Shahi Salman R, Kawahara T, et al. CRASH-2 (Clinical Randomisation of an Antifibrinolytic in Significant Haemorrhage) intracranial bleeding study: the effect of tranexamic acid in traumatic brain injury--a nested randomised, placebo-controlled trial. Health Technol Assess. 2012;16(13):iii-xii, 1-54. doi:10.3310/hta16130.

23. Pinder AJ, Dresner M, Calow C, Shorten GD, O'Riordan J, Johnson R. Haemodynamic changes caused by oxytocin during caesarean section under spinal anaesthesia. Int J Obstet Anesth. 2002;11(3):156-159. doi:10.1054/ijoa.2002.0970.

24. Ross J, Dallap BL, Dolente BA, Sweeney RW. Pharmacokinetics and pharmacodynamics of epsilon-aminocaproic acid in horses. Am J Vet Res. 2007;68(9):1016-1021. doi:10.2460/ajvr.68.9.1016.

25. Sayyah-Melli M, Ouladehsahebmadarek E, Taghavi $\mathrm{S}$, et al. The effect of intrauterine instillation of E-aminocaproeic acid during hysteroscopic operations in the management of intractable uterine hemorrhage: a randomized clinical trial. Life Sci J. 2013;1:10.

26. Shokeir T, El-Lakkany N, Sadek E, El-Shamy M, Abu Hashim H. An RCT: use of oxytocin drip during hysteroscopic endometrial resection and its effect on operative blood loss and glycine deficit. J Minim Invasive Gynecol. 2011;18(4):489-493. doi:10.1016/j. jmig.2011.03.015.

27. Sowter MC, Singla AA, Lethaby A. Pre-operative endometrial thinning agents before hysteroscopic surgery for heavy menstrual bleeding. Cochrane Database Syst Rev. 2013;11:CD010241. doi: 10.1002/14651858.cd001124.

28. Sweet MG, Schmidt-Dalton TA, Weiss PM, Madsen KP. Evaluation and management of abnormal uterine bleeding in premenopausal women. Am Fam Physician. 2012;85(1):35-43.

29. Thomas JS, Koh SH, Cooper GM. Haemodynamic effects of oxytocin given as i.v. bolus or infusion on women undergoing Caesarean section. Br J Anaesth. 2007;98(1):116-9. doi:10.1093/bja/ael302.

30. Triolo O, De Vivo A, Benedetto V, Falcone S, Antico F. Gestrinone versus danazol as preoperative treatment for hysteroscopic surgery: a prospective, randomized evaluation. Fertil Steril. 2006;85(4):1027-1031. doi: 10.1016/j.fertnstert.2005.09.034.

Copyright (c) 2016 The Author(s); This is an open-access article distributed under the terms of the Creative Commons Attribution License (http://creativecommons.org/licenses/by/4.0), which permits unrestricted use, distribution, and reproduction in any medium, provided the original work is properly cited. 